\title{
Clinical Gitelman Syndrome with Periodic Paralysis and Anemia
}

\section{Saiful Rahman, Leonita Anniwati}

Department of Clinical Pathology, Faculty of Medicine, Airlangga University/Dr. Soetomo Hospital, Surabaya, Indonesia. E-mail: ifoel.dr@gmail.com

\begin{abstract}
Gitelman syndrome is a rare, autosomal recessive, renal tubular salt-wasting disorder characterized by hypokalemia and metabolic alkalosis combined with hypomagnesemia and hypocalciuria. A 13-year-old male patient came with acute flaccid paralysis, pain, and weakness in limb muscles. Laboratory results showed hypokalemia, hypocalcemia, hypomagnesemia, and metabolic alkalosis accompanied by anemia and elevated serum transaminases. An electrocardiogram test showed a prolonged QT wave. Physical examination showed blood pressure 118/68 $\mathrm{mmHg}$; heart rate 95x/minute; respiration rate 26 $\mathrm{x} /$ minute; temperature $37.6^{\circ} \mathrm{C}$, weight $80 \mathrm{~kg}$, height $160 \mathrm{~cm}$, and BMI $31.25 \mathrm{~kg} / \mathrm{M}^{2}$. Neurological examination weakness in the lower limb, negative pathological reflex. Hematology examination showed $\mathrm{Hb} 9.8 \mathrm{~g} / \mathrm{dL}, \mathrm{MCV} 82.3 \mathrm{fL}, \mathrm{MCH} 26.8 \mathrm{pg}$, MCHC $32.5 \mathrm{~g} / \mathrm{dl}, \mathrm{WBC} 16.87 \times 10^{3} / \mu \mathrm{L}$, platelets $320 \times 10^{3} / \mu \mathrm{L}$, serum iron $47 \mathrm{mg} / \mathrm{dL}$, TIBC $229 \mathrm{mg} / \mathrm{dL}$, ferritin $38.45 \mathrm{ng} / \mathrm{mL}$. Peripheral blood smear showed hypochromic microcytic anemia. Blood gas pH 7.47; pCO2 39 mmHg; pO2 $44 \mathrm{mmHg}$; HCO3- 28.4 mmol/l; Beecf 4.7 mmol/l; SO2 83\%; AaDO2 114; thus supporting metabolic alkalosis. Cortisol level was 11.39 $\mathrm{ug} / \mathrm{dL}$, ANA test result was positive at $17.2 \mathrm{IU} / \mathrm{mL}$, the complement level was normal, dsDNA antigen was negative. Due to hypokalemia, hypocalcemia, hypomagnesemia, and metabolic alkalosis, this patient was diagnosed with Gitelman syndrome with anemia. The diagnosis should be confirmed by molecular DNA diagnostic studies to identify mutations of the gene encoding the thiazide-sensitive $\mathrm{Na}-\mathrm{Cl}$-cotransporter.
\end{abstract}

Keywords: Gitelman syndrome, periodic paralysis, hypokalemia, hypomagnesia, anemia

\section{INTRODUCTION}

Gitelman syndrome is an autosomal recessive disorder in the kidney characterized by clinical symptoms of normal or low blood pressure, decreased serum potassium, and magnesium levels accompanied by decreased urine calcium levels, and elevated blood $\mathrm{pH}$ levels. This is due to the mutation of the SLC12A3 gene located on chromosome $16 q 13$ encoding thiazide-sensitive sodium chloride cotransporter (NCC, NCCT, or TSC). The prevalence of Gitelman syndrome is estimated at 1:40,000 births and occurs in both males and females with an estimated incidence of approximately $1 \%$ in the Caucasian population. ${ }^{1}$

In many cases, symptoms of Gitelman syndrome do not appear before the age of 6 years, and usually, the diagnosis of this case is found in adolescence. Symptoms that appear in general are periodic muscle weakness accompanied by tetany, sometimes also accompanied by abdominal pain, vomiting, and fever. ${ }^{1,2}$

The diagnosis of Gitelman syndrome is based on clinical symptoms with laboratory tests that include hypokalemia, hypomagnesemia, metabolic alkalosis, and hypocalciuria. Bartter syndrome, especially type 3 , can be considered as a differential diagnosis in patients with Gitelman syndrome. ${ }^{1-3}$

\section{CASE}

A 13-year-old male patient with a complaint of body weakness since three days before hospital admission accompanied by the emergence of acute paralysis with pain in limb muscles one day before admission. The patient sometimes felt cramping in both leg muscles, unrelated to activity because the cramping easily disappeared without any treatment. Nausea-vomiting, diarrhea, and the use of drugs that cause frequent urination were denied. He also sometimes felt the presence of sudden fever without shivering, and the disappearance of the fever and chills after taking medicine was denied.

The previous history of kidney disorders, weakness, and paralysis, use of medicine, and vomiting was denied. There was no growth delay and learning difficulties. There was no history of high blood pressure, heart disease, diabetes, asthma, and hepatitis (jaundice). There was no family history of paralysis, muscle weakness, kidney disease, growth 
abnormalities, diabetes, heart disease, and asthma at ayoung age.

Physical examination in the emergency room revealed blood pressure 118/68 $\mathrm{mmHg}$; heart rate $95 \mathrm{x} /$ minute; respiration 26x / minute, weight $80 \mathrm{~kg}$, height $160 \mathrm{~cm}$, BMI $31.25 \mathrm{~kg} / \mathrm{M}^{2}$. Eyes: the conjunctiva was not pale, and the scleral jaundice was not found. Both pupils appeared isochronous with a $3 \mathrm{~mm}$ diameter with positive pupillary light reflex. No abnormalities were found in the ears, nose, and throat. Jugular venous pressure was $2-5 \mathrm{~mm}$ $\mathrm{H} 2 \mathrm{O}$, no palpable enlargement of the thyroid gland, and lymph nodes were found, the trachea was in the middle.

Chest examination revealed symmetrical chest movements in static and dynamic states with moderate breath depths of normal inspiratory and expiratory. Lung palpation showed right and left symmetrical fremitus, sonor percussion, normal lung, and liver. Auscultation showed vesicular breath sounds with no additional breath sounds. Cardiac examination revealed invisible ictus cordis, point of maximal impulse was at the lateral linea midclavicular sinistra as high as ICS V. Right border at linea sternalis dextra, upper limit as high as ICS III line midclavicular sinistra. Auscultation showed regular SI and SII, no murmur, and no gallop.

An abdominal examination found flat abdomen, soft, epigastrium positive tenderness, no enlargement of liver and lien, no shifting dullness, bowel sounds 4-6 times per minute. The extremities were warm, capillary refill time $<3$ seconds and there was no edema.

Neurologic examination revealed a physiological reflex of $+2 /+2$ in the upper extremities and $+1 /+$ 1 in the lower extremities, pathological reflex showed Chaddock reflex (-), Babinski reflex (-).

Chest $X$-ray was normal, a plain abdominal image with a conclusion: no abnormality detected. Ultrasound of the kidney and suprarenal was unremarkable; there was no nephrocalcinosis.

\section{DISCUSSIONS}

Table 1. Clinical chemistry tests

\begin{tabular}{|c|c|c|c|c|c|}
\hline \multirow{2}{*}{ Clinical Chemistry } & \multicolumn{4}{|c|}{ November (admission) } & \multirow{2}{*}{ Reference Range } \\
\hline & I & II & III & IV & \\
\hline BUN (mg/dL) & 14.3 & & 8.0 & & $10-20$ \\
\hline $\mathrm{SCr}(\mathrm{mg} / \mathrm{dL})$ & 1.15 & & 0.6 & & $0.6-1.3$ \\
\hline Albumin (g/dL) & & & 3.2 & & $3.4-5.0$ \\
\hline $\mathrm{Na}(\mathrm{mmol} / \mathrm{L})$ & 132 & 134 & 138 & 131 & $136-145$ \\
\hline $\mathrm{K}(\mathrm{mmol} / \mathrm{L})$ & 1.4 & 1.1 & 1.1 & 1.5 & $3.5-5.1$ \\
\hline $\mathrm{Cl}(\mathrm{mmol} / \mathrm{L})$ & 94 & 86 & 93 & 91 & $98-107$ \\
\hline Calcium (mg/dL) & & 7.1 & 7.0 & 6.7 & $8.5-10.1$ \\
\hline Magnesium & & 0.5 & 0.8 & 0.5 & $1.8-2.4$ \\
\hline AST $(U / L)$ & 1787 & & 294 & & $<50$ \\
\hline $\mathrm{ALT}(\mathrm{U} / \mathrm{L})$ & 419 & & 179 & & $<50$ \\
\hline Phosphate (mg/dL) & & & & & $10-20$ \\
\hline Urine uric acid (mg/24h) & & & & 1096 & $150-990$ \\
\hline Urine phosphate (mg/24h) & & & & 500 & $300-1000$ \\
\hline Urine creatinine (mg/24h) & & & & 1304 & $600-2000$ \\
\hline Urine calcium (mg/24h) & & & & 120 & $50-400$ \\
\hline Urine potassium (mg/24h) & & & & 25.6 & $35-80$ \\
\hline Urine sodium (mg/24h) & & & & 120 & $30-300$ \\
\hline Urine chloride (mg/24h) & & & & 160 & $85-170$ \\
\hline Serum iron $(\mathrm{mg} / \mathrm{dL})$ & & & 47 & & $35-150$ \\
\hline TIBC (mg/dL) & & & 229 & & $250-450$ \\
\hline
\end{tabular}


Table 2. Blood gas analysis

\begin{tabular}{lc}
\hline & Blood Gas Analysis \\
\hline Parameters & $\mathrm{I}$ \\
\hline $\mathrm{pH}$ & 7.47 \\
$\mathrm{pCO} 2(\mathrm{mmHg})$ & 39 \\
$\mathrm{pO} 2(\mathrm{mmHg})$ & 89 \\
$\mathrm{HCO}(\mathrm{mmol} / \mathrm{L})$ & 28.4 \\
$\mathrm{TCO} 2(\mathrm{mmol} / \mathrm{L})$ & 29.6 \\
$\mathrm{BEef}$ & 4.7 \\
$\mathrm{SO} 2(\%)$ & 83 \\
AaDO2 & 114 \\
Temp & 36.8 \\
\hline
\end{tabular}

Table 3. Hematology test

\begin{tabular}{lccc}
\hline \multicolumn{1}{c}{ Hematology } & I & II & III \\
\hline $\mathrm{Hb}(\mathrm{g} / \mathrm{dL})$ & 10.7 & 9.8 & 9.2 \\
$\mathrm{RBC}\left(\mathrm{X} 10^{6} / \mathrm{\mu L}\right)$ & 5.1 & 4.33 & 4.26 \\
$\mathrm{Hct}(\%)$ & 40.4 & 35.7 & 29.7 \\
$\mathrm{MCV}(\mathrm{fL})$ & 68 & 82.3 & 69.7 \\
$\mathrm{MCH}(\mathrm{pg})$ & 21.5 & 26.8 & 21.6 \\
$\mathrm{MCHC}(\mathrm{g} / \mathrm{dL})$ & 31.6 & 32.5 & 31.0 \\
$\mathrm{RDW}(\%)$ & 13.6 & 13.4 & 16.9 \\
$\left.\mathrm{WBC}(\mathrm{X} \mathrm{10})^{3} / \mu \mathrm{L}\right)$ & 17.59 & 16.87 & 14.47 \\
Neutrophil $(\%)$ & 88.8 & 83.4 & 80.5 \\
Lymph $(\%)$ & 6.4 & 8.9 & 11.2 \\
Mono $(\%)$ & 3.9 & 6.3 & 5.7 \\
Eo $(\%)$ & 0.2 & 0.2 & 0.25 \\
$\mathrm{Plt} \times 10^{3} / \mu \mathrm{L}$ & 312 & 302 & 297 \\
\hline
\end{tabular}

Table 4. Peripheral blood smear

\section{Peripheral Blood Smear}

\begin{tabular}{|c|c|}
\hline Erythrocyte & Hypochromic and microcytic anisopoikilocytosis \\
\hline Leukocyte & $\begin{array}{l}\text { Seems to be normal in number, dominated by segmented neutrophils, } \\
\text { immature granulocytes (-), atypical lymphocyte (-), blast (-) }\end{array}$ \\
\hline Thrombocyte & Seems to be normal in number, giant platelets $(+)$ \\
\hline Conclusion & Anemia: hypochromic microcytic and anisopoikilocytosis \\
\hline
\end{tabular}
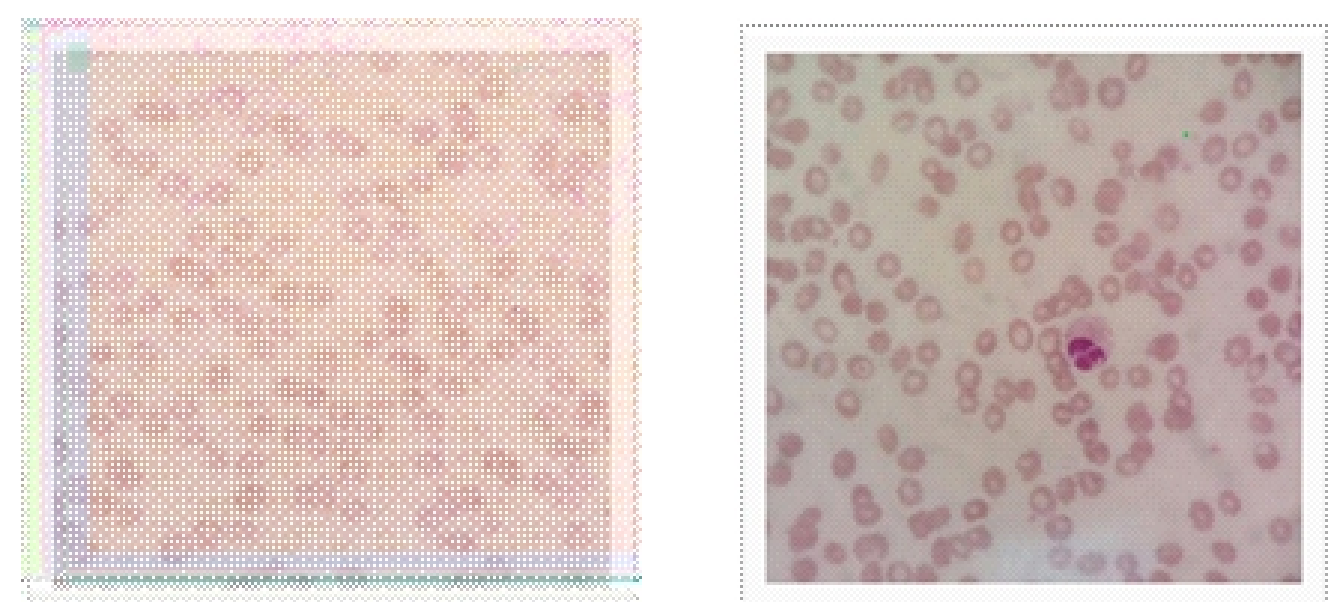

Figure 1. Peripheral blood smear with hypochromic microcytic erythrocytes 
Table 5. Immunology test

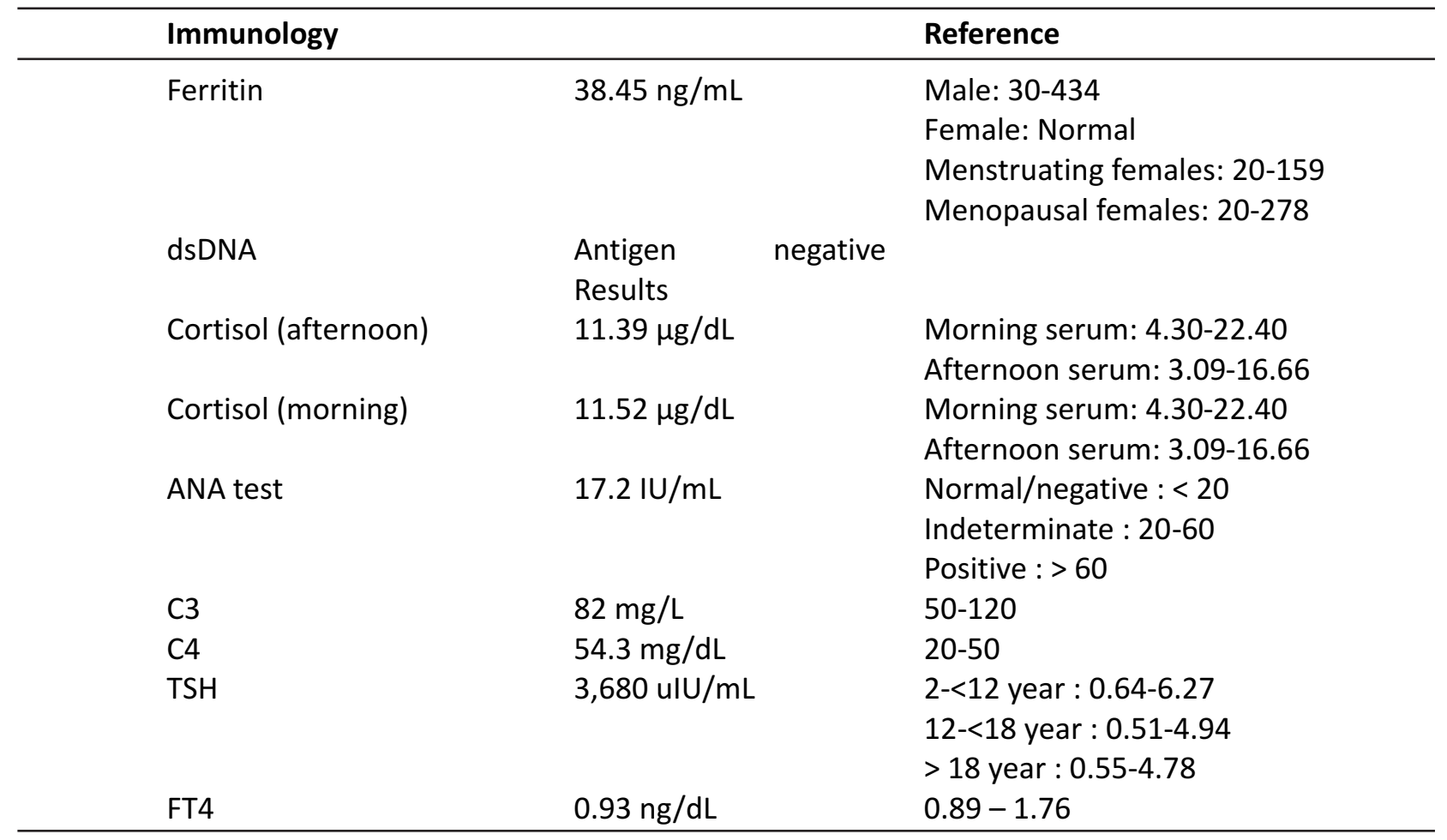

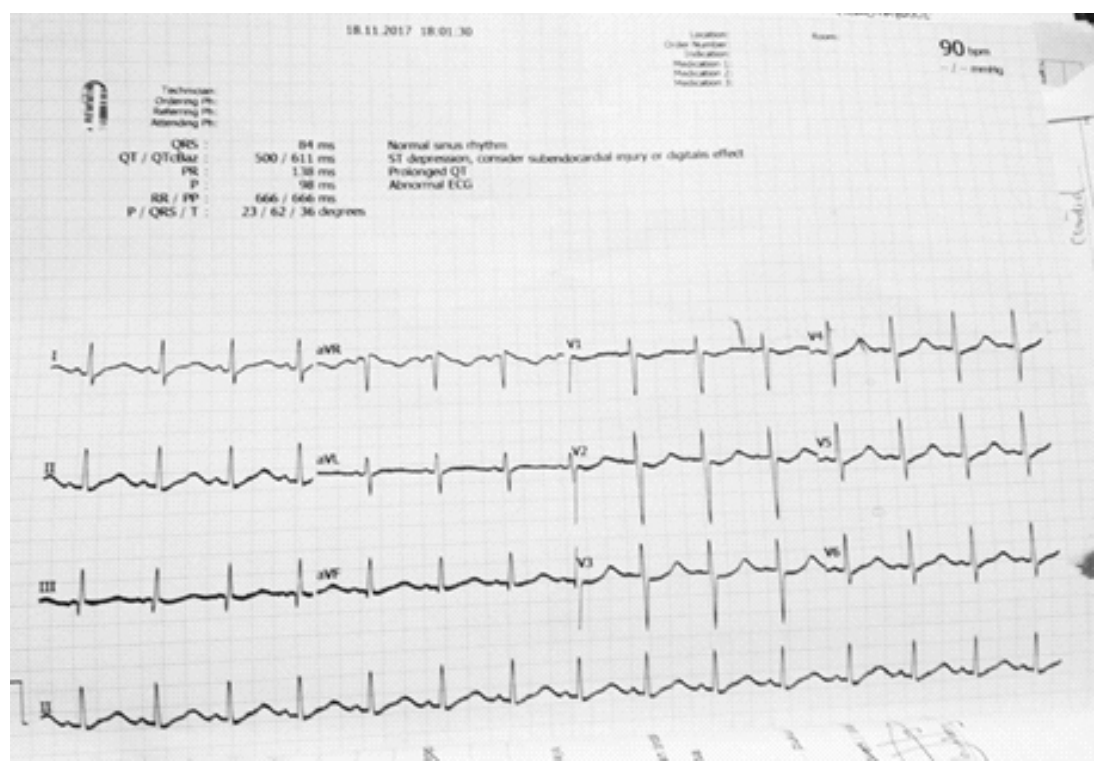

Figure 2. ECG with prolonged QT wave

Hypokalemia is a common clinical symptom, and the cause in most cases can be explained by patient history and physical examination or laboratory tests; however, the etiology in some cases requires a complete examination.

Gitelman syndrome is also known as familial hypokalemic hypomagnesemia because hypokalemia is the most common clinical symptom. However, because of its low prevalence, Gitelman's syndrome is rarely considered as a cause of muscle weakness and paralysis. This rare tubulopathy disorder is a common cause of hypokalemia that is often overlooked and can lead to paralysis or even death due to ventricular arrhythmias and cardiac arrest. ${ }^{4}$

Hypokalemia, hypomagnesemia, metabolic alkalosis, and accompanied by anemia, were found in this patient. Four possible mechanisms, which can cause hypokalemia are as follows: inadequate potassium intake (i.e. anorexia nervosa, long-term hunger), extracellular to an intracellular shift of potassium, non-renal loss (i.e. sweating, vomiting, and diarrhea), and excess renal potassium loss. ${ }^{5,6}$ 
Hypokalemia in this patient did not seem to be caused by poor intake. There was no long-term anorexia nervosa and vomiting. Shifting of cellular potassium might be associated with clinical hypokalemic periodic paralysis. Thyrotoxicosis did not occur because the thyroid function tests were normal. Chronic vomiting was also excluded because the patient did not have a history of continuous vomiting and high urinary chloride levels. The last possibility was caused by an increased loss of the kidney. ${ }^{5}$

Hyponatremia was described with GS for the first time by Schepkens et al. in 2001 in two patients. The phenotype of GS is identical to that of the chronic use of thiazide diuretics. Thiazide-induced hyponatremia has similar features to that of SIADH. Thiazides are "Saluretic", whereas frusemide causes water diuresis, "aquaretics". Various mechanisms have been attributed to thiazide-induced hyponatremia. Thiazide-induced hyponatremia occurs when the intake of free water is greater than the amount excreted by the kidneys. In subjects with moderate impairment of free-water excretion, a thiazide will cause hyponatremia if fluid intake is excessive. Hyponatremia can even be found in those with more serious impairment of free-water excretion with ordinary fluid intake.

Pantanetti et al. and Nakamura et al. describe two patients with GS in whom hypocalcemia developed due to hypomagnesemia. ${ }^{8}$ The combination of two rare complications, such as hyponatremia and hypocalcemia. Severe hypocalcemia is not generally present in this syndrome, whereas Calcium is found in body fluids in three different forms as follows: bound to proteins, complexed to low molecular-weight anions such as bicarbonate, and as a free molecule or ionized calcium, the only biologically active form. ${ }^{8}$ The amount of protein-bound calcium in circulation or complexed to bicarbonate increases along with the decline in hydrogen ion concentration and the increase in plasma bicarbonate, as in alkalosis. ${ }^{8,9}$

Both Bartter and Gitelman syndromes are a congenital aberration of the renal tubules that provide conditions of hypokalemia, metabolic alkalosis and may be accompanied by other clinical and biochemical abnormalities. Hypokalemia in this disorder is due to renal potassium wasting and normal blood pressure. Bartter's syndrome has so far been recognized to consist of 3 phenotypes: Antenatal Bartter syndrome is characterized by polyhydramnios and premature birth. During infancy, there is fever and dehydration episodes, as well as frequent growth retardation. Often secondary renal calcinosis occurs due to hypercalciuria; the face often shows the triangular shape, with prominent eyes and ears; Bartter classic syndrome occurs in childhood with symptoms of weakness and seizures due to hypokalemia. Polyuria and nocturia are common because hypokalemia caused by nephrogenic diabetes insipidus also often shows growth retardation; A variant of Bartter syndrome is Gitelman syndrome, which occurs in adolescence or adulthood, with milder symptoms. The dominant clinical sign is fatigue and weakness, distinguished by Bartter's syndrome with hypocalciuria, hypomagnesemia, as well as normal prostaglandin production. ${ }^{4,10,11}$

Molecular genetics suggests mutations in genes that encode specific ion transporter that provide two different clinical and physiologic features. The mutations in the potassium sodium-sensitive $\mathrm{Na}+-\mathrm{K}+2 \mathrm{Cl}$ - co-transporter provide phenotypic signs such as Bartter syndrome, the symptoms of metabolic alkalosis, hypokalemia, also accompanied by hypercalciuria and decreased intravascular volume in neonates. Mutation in thiazide-sensitive $\mathrm{Na} / \mathrm{Cl}$ cotransporter gene causes Gitelman syndrome, symptoms of metabolic alkalosis, hypokalemia accompanied by hypercalciuria, hypomagnesemia, whereas dominant symptoms and signs are found in the muscle. In these patients, there are metabolic alkalosis, hypokalemia. The condition corresponds to abnormalities in Barter and Gitelman syndrome. ${ }^{12}$

The ECG of this patient at the time of admission showed evidence of prolonged QTc interval (611 ms). Hypokalemia and hypomagnesemia simultaneously prolonged the potential duration of cardiomyocyte action and consequently increased the risk of ventricular arrhythmias. ${ }^{4,11}$ Bettinelli et al. found that patients showing a Qtc > 500 ms interval were at risk for such complications. ${ }^{10}$

The complete linkage between clinical signs in Gitelman syndrome and SCL12A3 mutations is now recognized that the potassium wasting is mediated by chronic renal salt-wasting and stimulation of Renin-Angiotensin-Aldosterone System (RAAS) as the consequence of relative hypovolemia., ${ }^{4,11,13,14}$ At the end of the RAAS cascade, aldosterone drive increases in the collecting tubule (Fig. 3), which will cause increased sodium reabsorption but causes enhanced potassium and hydrogen ions secretion accounting for hypokalemia and alkalosis found in affected patients. ${ }^{11}$ Symptoms in patients with Gitelman syndrome range from asymptomatic to mild symptoms of cramps and weakness to severe manifestation such as tetany, paralysis, and rhabdomyolisis. Salt craving, polydipsia, polyuria, and nocturia are also prominent symptoms. ${ }^{1,14}$

The difference between these two diseases can be seen in Table 6, which shows distinct clinical symptoms between the two based on abnormalities in the gene mutation. ${ }^{15}$ 
Tabel 6. Differences in Bartter syndrome type 3 and Gitelman syndrome ${ }^{15}$

\begin{tabular}{|c|c|c|c|c|c|}
\hline & $\begin{array}{l}\text { Gene } \\
\text { Product }\end{array}$ & $\begin{array}{l}\text { Gene } \\
\text { Mutation }\end{array}$ & $\begin{array}{l}\text { Chromosome } \\
\text { Band }\end{array}$ & $\begin{array}{l}\text { Inheritance } \\
\text { /OMIM }\end{array}$ & $\begin{array}{l}\text { Clinical } \\
\text { Characteristics }\end{array}$ \\
\hline $\begin{array}{l}\text { Bartter syndrome (alias) } \\
\text { Type } 1 \text { (antenatal Bartter } \\
\text { syndrome; } \\
\text { hyperprostaglandin E } \\
\text { syndrome }\end{array}$ & $\mathrm{NKCC2}$ & SLC12A1 & $15 q 21.1$ & AR/601678 & $\begin{array}{l}\text { Polyhydramnios, } \\
\text { prematurity, polyuria, } \\
\text { nephrocalcinosis }\end{array}$ \\
\hline $\begin{array}{l}\text { Type } 2 \text { (neonatal Bartter } \\
\text { syndrome with transient } \\
\text { hyperkalemia, } \\
\text { hyperprostaglandin E } \\
\text { syndrome) }\end{array}$ & ROMK & KCNJ1 & $11 q 24.3$ & AR/241200 & $\begin{array}{l}\text { Polyhydramnios, } \\
\text { prematurity, polyuria, } \\
\text { nephrocalcinosis, transient } \\
\text { hyperkalemic acidosis }\end{array}$ \\
\hline $\begin{array}{l}\text { Type } 3 \text { classic Bartter } \\
\text { syndrome }\end{array}$ & $\mathrm{CIC}-\mathrm{Kb}$ & CLCNKB & $1 p 36.13$ & $\begin{array}{l}\text { AR: many are } \\
\text { sporadic/607 } \\
364\end{array}$ & $\begin{array}{l}\text { Birth at term, no } \\
\text { nephrocalcinosis }\end{array}$ \\
\hline $\begin{array}{l}\text { Type } 4 \text { (antenatal Bartter } \\
\text { syndrome; } \\
\text { hyperprostaglandin E } \\
\text { syndrome with } \\
\text { sensorineural deafness, } \\
\text { BART }\end{array}$ & $\begin{array}{l}\text { Barttin (b } \\
\text { subunit of } \\
\text { CIC-Ka } \\
\text { and CIC-Kb }\end{array}$ & BSND & $1 q 32.3$ & $\begin{array}{l}\text { AR/602522; } \\
\text { digenic in } \\
\text { CLCNKA and } \\
\text { CLCNKB } \\
\text { genes }\end{array}$ & $\begin{array}{l}\text { Prematurity, sensorineural } \\
\text { deafness, no } \\
\text { nephrocalcinosis }\end{array}$ \\
\hline $\begin{array}{l}\text { Type } 5 \text { (hypocalcemia with } \\
\text { Bartter like syndrome) }\end{array}$ & CASR & L125P & $3 q 21.1$ & $A D / 601199$ & $\begin{array}{l}\text { Hypocalcemia suppressed } \\
\text { PTH }\end{array}$ \\
\hline Gitelman syndrome & NCCT & SLC12A3 & $16 q 13$ & $A R / 263800$ & $\begin{array}{l}\text { Hypocalciuria, } \\
\text { hypermagnesiuria, } \\
\text { hypomagnesemia }\end{array}$ \\
\hline
\end{tabular}

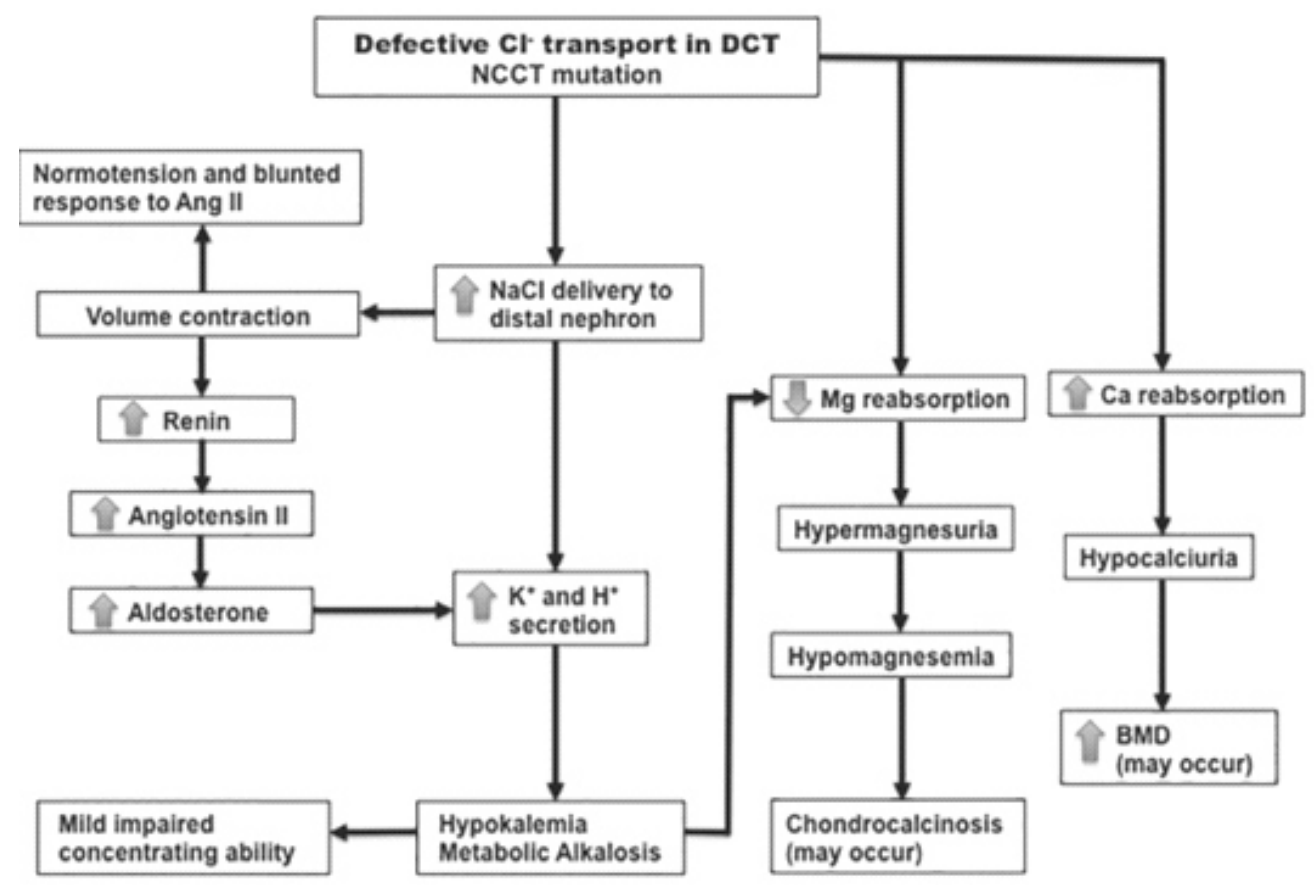

Figure 3. Pathophysiology of Gitelman syndrome. The primary abnormality is defective $\mathrm{Cl}$ - reabsorption in the DCT due to inactivated mutations in the NCCT gene. This leads to the main features of the syndrome, such as hypokalemic metabolic alkalosis, secondary hyperaldosteronism, normotension, hypomagnesemia, hypocalciuria, and blunted response to angiotensin II. DCT, distal convoluted tubule; NCCT, thiazide-sensitive Na-Cl cotransporter ${ }^{11}$ 


\section{CONCLUSION}

In short, Gitelman syndrome is one of the rare causes of hypokalemia. Although it is a congenital disorder, salt-losing tubulopathy may emerge in adulthood and should be recorded in the diagnosis of hypokalemia. This patient is an example of Gitelman syndrome with severe hypokalemia, hypomagnesemia, and periodic paralysis. Assessment of serum electrolytes, including magnesium, renal potassium evaluation, and calcium excretion, acid-base analysis, and the presence of secondary hyperaldosteronism are essential in the approach of the patient with hypokalemic paralysis. If possible, the diagnosis should be performed at the genetic level. Dynamic studies with diuretic challenge tests can be a diagnostic aid when mutation studies are not available. The appropriate treatment protects the patient from potentially harmful complications.

\section{REFERENCES}

1. Knoers NVAM, Levtchenko EN. Gitelman syndrome. Orphanet J Rare Dis. 2008; 3(1): 1-6.

2. Graziani G, Fedeli C, Moroni L, Cosmai L, Badalamenti S, Ponticelli C. Gitelman syndrome: Pathophysiological and clinical aspects. QJM, 2010; 103(10): 741-8.

3. Skalova S, Neuman D, Lnenicka P, Stekrova J. Gitelman syndrome as a cause of psychomotor retardation in a toddler. Arab J Nephrol Transplant, 2013; 6(1): 37-9.

4. Nakhoul F, Nakhoul N, Dorman E, Berger L, Skorecki K, Magen D. Gitelman's syndrome: A pathophysiological and clinical update. Endocrine, 2012; 41(1): 53-7.

5. Aoki K, Tajima T, Yabushita Y, Nakamura A, Nezu U, et al. A novel initial codon mutation of the thiazide-sensitive $\mathrm{Na}-\mathrm{Cl}$ cotransporter gene in a Japanese patient with Gitelman's syndrome. Endocr J, 2008; 55(3): 557-60.

6. Greenlee $\mathrm{M}$, Wingo $\mathrm{CS}, \mathrm{McD}$ onough $\mathrm{AA}$, Youn $\mathrm{JH}$, Kone BC. Narrative review: Evolving concepts in potassium homeostasis and hypokalemia. Ann Intern Med, 2009; 150(9): 619-25.

7. Abdulla. Severe hyponatremia and hypocalcemia in Gitelman syndrome: A case report. World J Nephrol Urol [Internet]. 2014; 3: 110-2. Available from: http://www.wjnu.org/index.php/wjnu/article/view/ 149 (accessed 25 November, 2017).

8. Pantanetti P, Arnaldi G, Balercia G, Mantero F, Giacchetti G. Severe hypomagnesaemia-induced hypocalcaemia in a patient with Gitelman's syndrome. Clin Endocrinol (Oxf), 2002; 56(3): 413-8.

9. Ali A, Masood Q, Yaqub S, Kashif W. A case of Gitelman syndrome with severe hyponatraemia and hypophosphataemia. Singapore Med J, 2013; 54(1): 18-20.

10. Bettinelli A, Bianchetti MG, Girardin E, Caringella A, Cecconi $M$, et al. Use of calcium excretion values to distinguish two forms of primary renal tubular hypokalemic alkalosis: Bartter and Gitelman syndromes. J Pediatr, 1992; 120(1): 38-43.

11. Shaer AJ. Inherited primary renal tubular hypokalemic alkalosis: A review of Gitelman and Bartter syndromes. Am J Med Sci, 2001; 322(6): 316-32.

12. Seyberth HW, Weber S, Kömhoff M. Bartters and Gitelmans syndrome. Curr Opin Pediatr [Internet]. 2017; 29(2): 179-86. Available from: http://journals.lww.com/00008480-201704000-00010 (accessed 22 November, 2017).

13. UNWIN R, CAPASSO G. Bartter's and Gitelman's syndromes: their relationship to the actions of loop and thiazide diuretics. Curr Opin Pharmacol [Internet]. 2006; 6(2): 208-13. Available from: https://linkinghub.elsevier.com/retrieve/pii/S147148 9206000300 (accessed 24 November, 2017).

14. Simon DB, Nelson-Williams $C$, Johnson Bia M, Ellison $D$, Karet $F E$, et al. Gitelman's variant of Barter's syndrome, inherited hypokalaemic alkalosis, is caused by mutations in the thiazide-sensitive $\mathrm{Na}-\mathrm{Cl}$ cotransporter. Nat Genet [Internet]. 1996; 12(1): 24-30. Available from: http://www.nature.com/articles/ ng0196-24 (accessed 23 November, 2017).

15. Fremont OT, Chan JCM. Understanding Bartter syndrome and Gitelman syndrome. World Journal of Pediatrics, 2012; 8: 25-30. 